\title{
A Two-Dimensional Multiphysics Coupling Model of a Middle and Low Temperature Solar Receiver/Reactor for Methanol Decomposition
}

\author{
Yanjuan Wang ${ }^{1}$, Qibin Liu ${ }^{2, *}$, Jing Lei ${ }^{1}$, Jiwei Li $^{1}$ and Can Chen ${ }^{3}$ \\ 1 School of Energy, Power and Mechanical Engineering, North China Electric Power University, \\ Changping District, Beijing 102206, China; 90102184@ncepu.edu.cn (Y.W.); \\ leijing2002@gmail.com (J.Lei); 1111171106@ncepu.edu.cn (J.Li) \\ 2 Institute of Engineering Thermophysics, Chinese Academy of Sciences, Beijing 100190, China \\ 3 State Grid Information \& Telecommunication Branch, Beijing 100761, China; chencan@sgcc.com.cn \\ * Correspondence: qibinliu@mail.etp.ac.cn; Tel.: +86-10-8254-3031
}

Received: 16 September 2017; Accepted: 21 October 2017; Published: 25 October 2017

\begin{abstract}
In this paper, the endothermic methanol decomposition reaction is used to obtain syngas by transforming middle and low temperature solar energy into chemical energy. A two-dimensional multiphysics coupling model of a middle and low temperature of $150 \sim 300{ }^{\circ} \mathrm{C}$ solar receiver/reactor was developed, which couples momentum equation in porous catalyst bed, the governing mass conservation with chemical reaction, and energy conservation incorporating conduction/convection/radiation heat transfer. The complex thermochemical conversion process of the middle and low temperature solar receiver/reactor (MLTSRR) system was analyzed. The numerical finite element method (FEM) model was validated by comparing it with the experimental data and a good agreement was obtained, revealing that the numerical FEM model is reliable. The characteristics of chemical reaction, coupled heat transfer, the components of reaction products, and the temperature fields in the receiver/reactor were also revealed and discussed. The effects of the annulus vacuum space and the glass tube on the performance of the solar receiver/reactor were further studied. It was revealed that when the direct normal irradiation increases from $200 \mathrm{~W} / \mathrm{m}^{2}$ to $800 \mathrm{~W} / \mathrm{m}^{2}$, the theoretical efficiency of solar energy transformed into chemical energy can reach $0.14-0.75$. When the methanol feeding rate is $13 \mathrm{~kg} / \mathrm{h}$, the solar flux increases from $500 \mathrm{~W} / \mathrm{m}^{2}$ to $1000 \mathrm{~W} / \mathrm{m}^{2}$, methanol conversion can fall by $6.8-8.9 \%$ with air in the annulus, and methanol conversion can decrease by $21.8-28.9 \%$ when the glass is removed from the receiver/reactor.
\end{abstract}

Keywords: solar receiver/reactor; methanol decomposition; middle and low temperature thermochemical processes

\section{Introduction}

Solar thermochemical processes can be used to obtain chemical fuel by transforming middle and low temperature solar energy into chemical energy of the syngas for storing and transporting solar energy. Steinfeld and Fletcher have made an earlier research in this field, respectively [1,2]. The solar reactor is the most part of the solar thermochemical process, now, the pivotal issue on improving the properties of the solar reactor has been obtained great attention, thus, a lot of research on the solar reactor has been implemented [3-9]. For instance, a scalable and simple solar reactor, which uses porous ceria as catalyst was proposed by Chueh et al. The porous ceria was directly exposed to the high-temperature concentrated solar energy, which improves the heat transfer performance of catalyst. They also investigated the viability of a thermochemical cycle driven by solar energy for dissociating water and carbon dioxide using nonstoichiometric ceria. 
The solar-to-fuel energy conversion efficiency observed in this work is improved by about two orders of magnitude when compared with that obtained by state-of-the-art photocatalytic method [3]. Hirsch et al. addressed the concept and fabrication of a solar reactor for the thermal decomposition of natural gas into carbon and hydrogen using concentrated solar energy. The feasibility of the solar reactor design for continuous operation was tests with a $5 \mathrm{~kW}$ prototype [4]. An original solar receiver prototype was developed by Lanchi et al., which used AISI 316 to support the design of an Inconel prototype. This system obtained good thermal inertia and achieved a quite uniform distribution of temperature in the annular channel [5]. However, these solar thermochemical processes can be achieved at very high temperatures of above $800 \mathrm{~K}$, using concentrated solar radiation, thus imposing technological difficulties of coupling solar energy as the driving energy for the chemical reactions. Now, Jin and his group developed a new approach for hydrogen production by using middle and low temperature concentrated solar energy [6-8]. A first MLTSRR prototype has been manufactured by Jin et al. [9], furthermore, the basic principle of the MLTSRR is identified.

In order to further optimize the performance of the MLTSRR, in this paper, the key issue on the property of the MLTSRR is investigated, and the main work is summarized as:

(1) To reveal the fluid dynamic, thermal and chemical reaction characteristics of the MLTSRR, a mathematical model for analyzing the properties of the MLTSRR is implemented by the finite element method (FEM), which couples momentum equation in porous catalyst bed, the governing mass conservation with chemical reaction, and energy conservation incorporating conduction/convection/radiation heat transfer.

(2) Two approaches of methanol for solar energy utilization: methanol decomposition and methanol steam reforming with direct normal irradiation (DNIs) were compared.

(3) The effects of the annulus vacuum space and the glass tube on the properties of the middle and low temperature solar receiver/reactor (MLTSRR) were disclosed.

\section{Physical Model of the MLTSRR}

\subsection{Configuration of the MLTSRR}

The MLTSRR, as shown in Figure 1, is the most part of the endothermic methanol decomposition reaction. The MLTSRR mainly consists of a solar tracking reflector and a fixed-bed receiver/reactor, which is located at the focal line of the solar tracking reflector. The solar tracking reflector is used to concentrate the middle and low temperature solar radiation for methanol decomposition. The tubular receiver is also the chemical reactor, laden with porous catalyst made of $\mathrm{Cu} / \mathrm{ZnO} / \mathrm{Al}_{2} \mathrm{O}_{3}$. The detailed dimensions of the receiver/reactor are listed in Table 1.

$$
\mathrm{CH}_{3} \mathrm{OH} \rightarrow 2 \mathrm{H}_{2}+\mathrm{CO}, \Delta_{r} \mathrm{H}_{298 \mathrm{~K}}=91 \mathrm{~kJ} / \mathrm{mol}
$$

Table 1. Typical dimensions of the MLTSRR.

\begin{tabular}{cc}
\hline Items & Parameter \\
\hline Mirror reflectivity & 0.93 \\
Aperture Length [m] & 4 \\
Aperture Width [m] & 2.5 \\
Glass tue's outer diameter [m] & 0.115 \\
glass tube's inner diameter [m] & 0.109 \\
Reactor's outer diameter [m] & 0.07 \\
Reactor's inner diameter [m] & 0.065 \\
Coating absorbance & 0.95 \\
Glass tube's transmittance & 0.95 \\
Coating emissivity [ $\left.{ }^{\circ} \mathrm{C}\right]$ & $0.04795+0.0002331 T$ \\
\hline
\end{tabular}




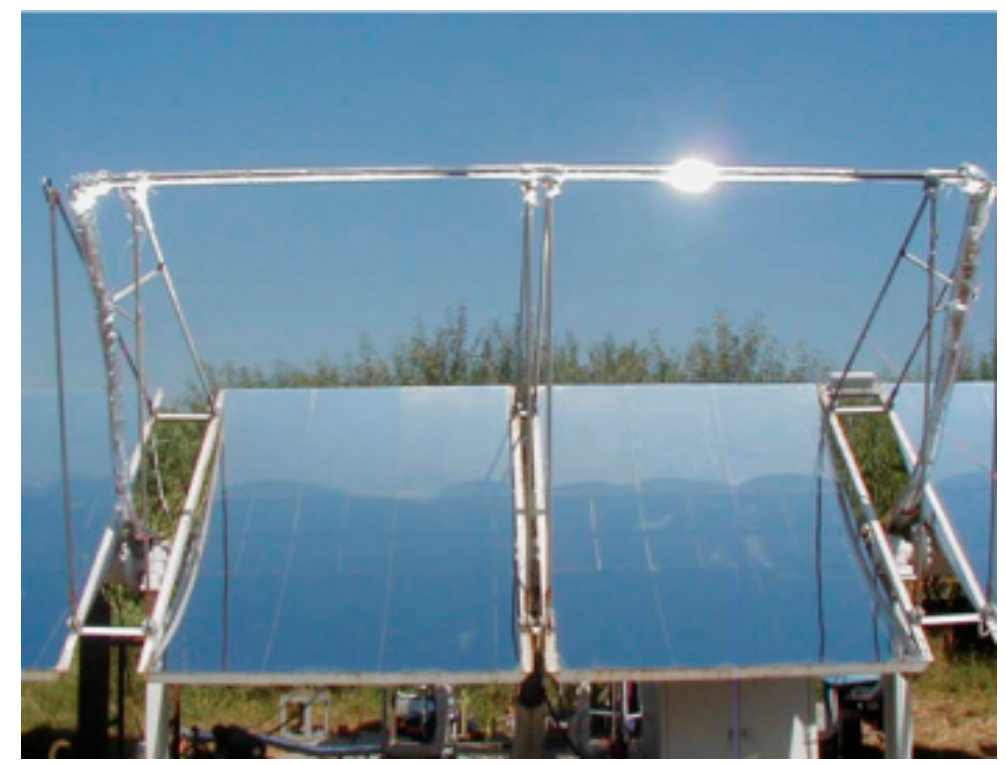

Figure 1. Configuration of the middle and low temperature solar receiver/reactor (MLTSRR).

\subsection{Multiphysics Coupling Model of the MLTSRR}

A mathematical model for analyzing the properties of the MLTSRR is implemented to analyze the energy transforming process of the middle and low temperature solar energy into chemical energy in the MLTSRR, as shown in Figure 2, the process includes: the solar energy absorption in the glass tube; the heat transfer process between the glass tube and the porous catalyst bed, chemical reaction and the coupling convection/conduction heat transfer in the porous catalyst bed; conduction heat transfer in the receiver/reactor tube and the glass tube; the coupling convection/conduction/radiation heat transfer in the evacuated space; and, the coupling convection/radiation heat transfer from the glass tube to the atmosphere.

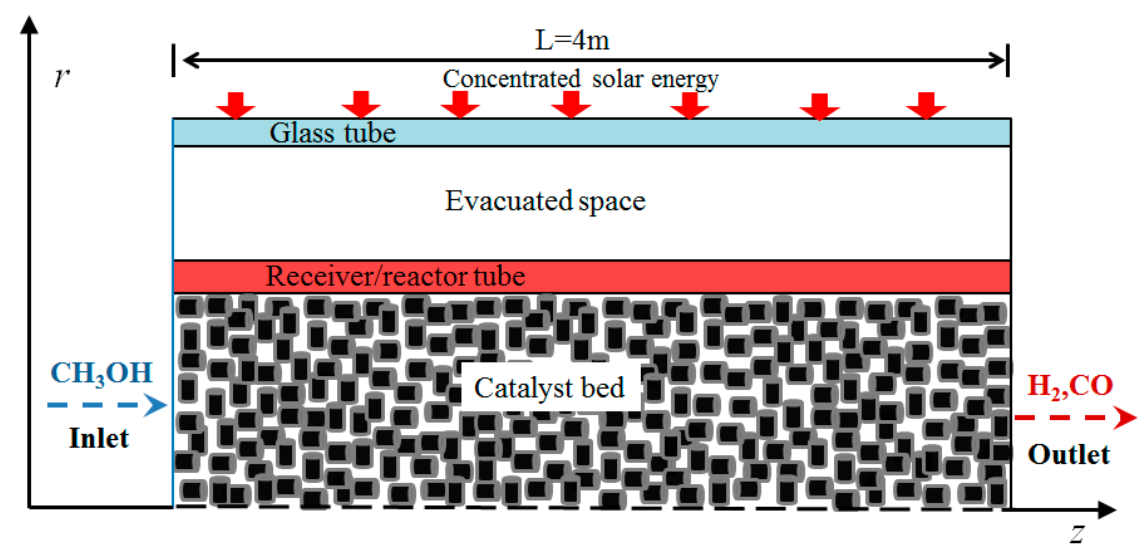

Figure 2. Coupling model of the MLTSRR.

The main governing equations are formulated as:

Continuity equation:

$$
\nabla \cdot \vec{u}=0
$$

Darcy's law is used to describe the flow of gaseous species in the porous catalyst bed, the flow parameters and the properties of the gaseous species are averaged over a control volume. As shown in 
Equation (2), the velocity distributions depend on the fluid viscosity, the pressure gradient, and the structure of the porous catalyst bed. The momentum equation was described by:

$$
u=-\frac{\kappa}{\eta}\left(\frac{\partial p}{\partial x}+\frac{\partial p}{\partial y}+\frac{\partial p}{\partial z}\right)
$$

where $p$ is the pressure $(\mathrm{Pa}), u$ represents the velocity $(\mathrm{m} / \mathrm{s}), \eta$ stands for the dynamic viscosity $(\mathrm{kg} /(\mathrm{m} \cdot \mathrm{s}))$ and the hydraulic permeability $\kappa\left(\mathrm{m}^{2}\right)$ can be formulated as [10]:

$$
\kappa=\frac{d_{p}^{2} \varepsilon^{3}}{150(1-\varepsilon)^{2}}
$$

where $d_{p}$ represents the equivalent diameter of the catalyst particles; $\varepsilon$ stands for the porosity of the catalyst bed.

Chemical reaction and coupling conduction/convection heat transfer occur simultaneously in the porous catalyst bed. We assume the porous catalyst bed to be isotropic and homogeneous [11], so the energy conversion equation was as follows:

$$
\begin{gathered}
-k_{s} \frac{\partial}{\partial x_{i}}\left(\frac{\partial T_{s}}{\partial x_{i}}\right)+\left(\rho C_{p}\right)_{f} u_{i} \frac{\partial T_{s}}{\partial x_{i}}=Q \\
Q=\Delta H_{r} \cdot r
\end{gathered}
$$

where $Q$ stands for a heat source $\left(\mathrm{W} / \mathrm{m}^{3}\right)$ due to the chemical reaction; the indices " $f$ " represents gaseous phases; $u$ denotes the fluid velocity $(\mathrm{m} / \mathrm{s}) ; T_{\mathrm{S}}$ denotes the temperature $(\mathrm{K})$ of the catalyst bed; $k_{s}$ is the conduction coefficient of the catalyst bed $(\mathrm{W} /(\mathrm{m} \cdot \mathrm{K})) ; \Delta H_{r}$ is the enthalpy of reaction $(\mathrm{J} / \mathrm{mol})$, and $r$ represents the reaction rate $\left(\mathrm{mol} /\left(\mathrm{m}^{3} \cdot \mathrm{s}\right)\right)$.

Kinetic investigations on methanol decomposition employing $\mathrm{Cu} / \mathrm{ZnO} / \mathrm{Al}_{2} \mathrm{O}_{3}$ as catalyst have been studied by a lot of researchers in detail. An overall kinetic model of decomposition is used solely, which can be formulated as:

$$
r_{D}=\frac{\left.k_{D} K_{\mathrm{CH}_{3} \mathrm{O}(2)}^{*}\left(p_{\mathrm{CH}_{3} \mathrm{OH}} / p_{\mathrm{H}_{2}}^{1 / 2}\right)\left(1-p_{\mathrm{H}_{2}}^{2} p_{\mathrm{CO}} / k_{D} p_{\mathrm{CH}_{3} \mathrm{OH}}\right) C_{S_{2}}^{T} C_{S_{2 a}}^{T}\right)}{\left(1+K_{\mathrm{CH}_{3} \mathrm{O}^{(2)}}^{*}\left(p_{\mathrm{CH}_{3} \mathrm{OH}} / p_{H_{2}}^{1 / 2}\right)+K_{\mathrm{OH}^{(2)}}^{*}\left(p_{\mathrm{H}_{2} \mathrm{O}} / p_{H_{2}}^{1 / 2}\right)\right)\left(1+K_{H^{2 a}}^{1 / 2} p_{H_{2}}^{1 / 2}\right)}
$$

The parameters in Equation (6) can be calculated by [12]:

$$
\begin{gathered}
k_{D}=k_{D}^{\infty} \exp \left(\frac{-E_{D}}{R T}\right) \\
K_{C H_{3} O^{(2)}}^{*}=\exp \left(\frac{\Delta S_{{ }_{C H} \mathrm{O}^{(2)}}^{*}}{R}+\frac{\Delta H_{C H_{3} \mathrm{O}^{(2)}}^{*}}{R T}\right) \\
K_{H^{2 a}}=\exp \left(\frac{\Delta S_{H^{2 a}}}{R}+\frac{\Delta H_{H^{2 a}}}{R T}\right)
\end{gathered}
$$

where $T$ represents the temperature of the solar receiver/reactor, $r_{D}$ stands for the reaction rate of the methanol; $p_{i}$ defines the partial pressure of component $i$; and, $R$ is the universal gas constant. Table 2 shows the parameters of Equations (6)-(9). 
Table 2. Variables of the methanol decomposition kinetic model.

\begin{tabular}{|c|c|c|}
\hline $\begin{array}{c}\text { Rate Constant or } \\
\text { Equilibrium Constant }\end{array}$ & $\begin{array}{c}\Delta S_{i}\left(\mathrm{~J} \mathrm{\textrm {mol } ^ { - 1 }} \mathrm{K}^{-1}\right) \text { or } \\
k_{i}^{\infty}\left(\mathrm{m}^{2} \mathrm{~s}^{-1} \mathrm{~mol}^{-1}\right)\end{array}$ & $\Delta H_{i}$ or $E\left(\mathrm{~kJ} \mathrm{~mol}^{-1}\right)$ \\
\hline$k_{D}\left(\mathrm{~m}^{2} \mathrm{~s}^{-1} \mathrm{~mol}^{-1}\right)$ & $3.8 \times 10^{20}$ & 170 \\
\hline$K_{\mathrm{CH}_{3} \mathrm{O}^{(2)}}^{*}\left(\mathrm{bar}^{-0.5}\right)$ & 30.0 & -20.0 \\
\hline$K_{O H^{(2)}}^{*}\left(\operatorname{bar}^{-0.5}\right)$ & 30.0 & -20.0 \\
\hline$K_{H^{2 a}}^{*}\left(\operatorname{bar}^{-0.5}\right)$ & -46.2 & -50.0 \\
\hline
\end{tabular}

The mass balance equations account for mass transport including diffusion according to the Maxwell-Stefan diffusion [13] and convection. The multi-component diffusivity coefficient has been investigated by Fuller, et al. [14].

As for the outer surface of the receiver/reactor tube, the average solar energy flux boundary condition and radiation are used. The conduction boundary condition is used in the receiver/reactor tube and the glass tube.

The other boundary conditions are: at the inner surface of the receiver/reactor tube, thermal wall function is used; as for the glass tube's outer surface, mixed boundary condition of convection and radiation are applied; and, thermal insulation is assumed for the tube ends. It is worth mentioning that the surface-to-surface radiation is applied between the receiver/reactor tube's outer surfaces and glass tube's inner surfaces. At the glass tube's outer surface, surface-to-ambient radiation is applied, meaning that there is no reflected radiation from the ambient.

\subsection{Numerical Methods}

The material properties of the tube, as well as the parameters of the gaseous species, such as conductivity, specific heat capacity, density, and viscosity are functions of temperature. A damped Newton method is applied for solving the problem. The convergence criterion for all of the solved parameters is that the tolerance is smaller than $10^{-3}$.

The methanol conversion rate can be calculated:

$$
\mathrm{X}_{\mathrm{CH}_{3} \mathrm{OH}}=\frac{n_{\mathrm{CH}_{3} \mathrm{OH}}-n_{u n, \mathrm{CH}_{3} \mathrm{OH}}}{n_{\mathrm{CH}_{3} \mathrm{OH}}}
$$

To further investigate the thermochemical property of the proposed thermochemical process, the thermochemical efficiency of $\eta_{s o-c h}$, described as the portion of concentrated solar energy transformed into chemical energy, is defined as:

$$
\eta_{s o-c h}=\frac{X_{\mathrm{CH}_{3} \mathrm{OH}} n_{\mathrm{CH}_{3} \mathrm{OH}} \Delta_{r} \mathrm{H}}{I S_{\mathrm{A}}}
$$

where $S_{A}$ stands for the effective area of the concentrators; $I$ is the solar flux; $\Delta_{r} H$ denotes the enthalpy of reaction corresponding to per mole of the reactant at the temperature of $T_{\text {Reactor; }}$ and, the pressure $p$ in $\mathrm{J} / \mathrm{mol}$.

To validate that the numerical program can deal with the methanol conversion in the MLTSRR, the numerical FEM model is validated by comparing the experimental data from Liu et al. The numerical conditions are the same as the experiment conditions. The comparisons between the simulations and experiments are shown in Figure 3, the numerical results on the methanol conversion agree reasonably well with that of the experimental results. This result gives one confidence in the use of the present numerical program. 


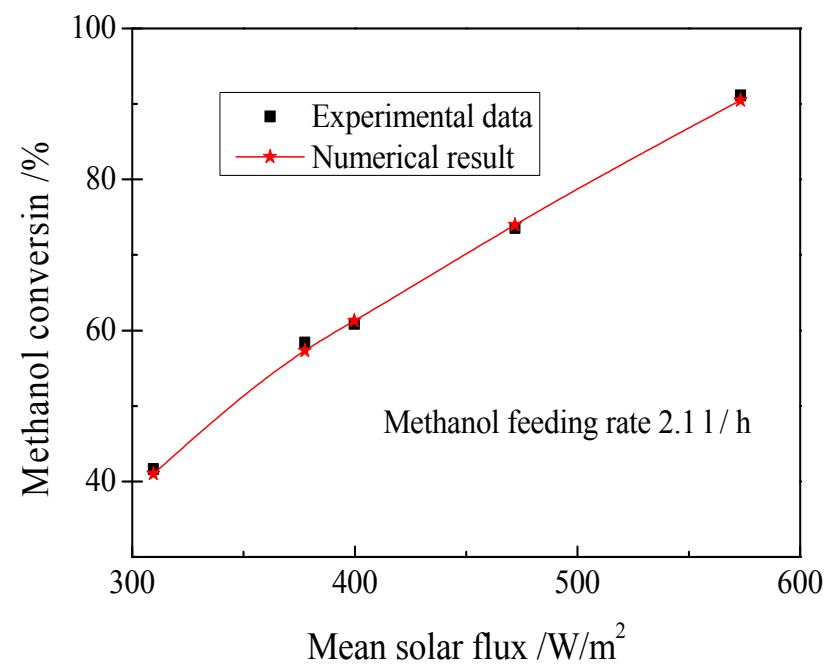

Figure 3. Comparison of the methanol conversion between the numerical model and experiment.

\section{Results and Discussion}

\subsection{Thermochemical Properties of the MLTSRR}

In order to study the thermochemical property of the MLTSRR, we choose a typical working condition: the reactants feeding rate of methanol, the reactants inlet temperature and the direct normal irradiation (DNI) are $11.3 \mathrm{~kg} / \mathrm{h}, 433 \mathrm{~K}$ and $800 \mathrm{~W} / \mathrm{m}^{2}$, respectively.

The temperature distribution of the MLTSRR affects the thermochemical properties of the MLTSRR. Figure 4 shows the temperature distributions of the receiver/reactor. As can be seen from Figure 4, the temperature rises rapidly in the beginning of the solar receiver/reactor, and then it increases gently. Based on the energy conservation principle, the concentrated solar energy is divided into two parts: one drives the endothermic methanol decomposition reaction and the other heats the gaseous species. In the beginning of the MLTSRR, because of the low methanol conversion with small reaction enthalpy, heating the gaseous species dominates. Then, with the increase of the temperature, the reaction rate increases, so that most of energy is provided for driving the endothermic reaction, and a small amount of solar thermal energy is used to heat the gaseous species, thus, the temperature increases gently.

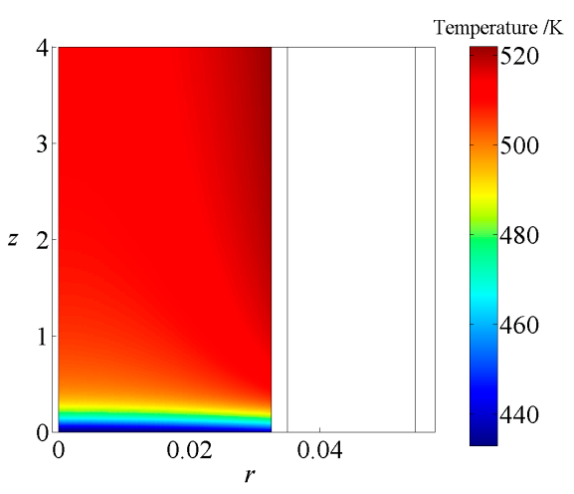

(a)

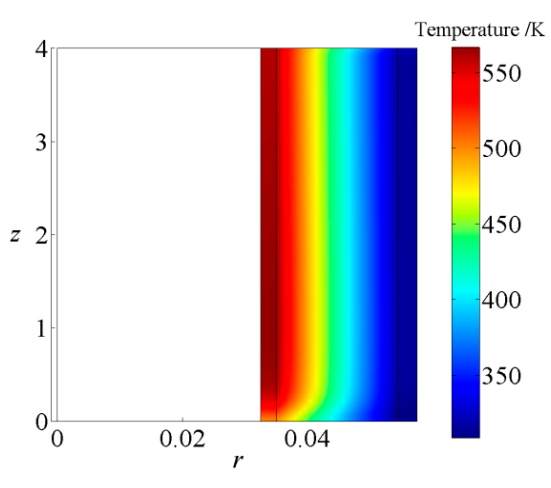

(b)

Figure 4. Temperature distributions of the MLTSRR. (a) Catalyst bed; (b) Receiver/reactor tube and glass tube.

Figure $4 \mathrm{~b}$ shows the temperature distributions of the receiver/reactor tube and glass cover tube. The temperature increases along the main flow direction. The temperatures of receiver/reactor tube 
are much higher than that of the glass tube, leading to the decreasing of the heat loss to the ambient, especially the heat loss of radiation. In this case, the convective heat loss is about $85.26 \mathrm{~W} / \mathrm{m}$, and the radiation heat loss is about $43.31 \mathrm{~W} / \mathrm{m}$, the theoretical thermochemical efficiency for methanol decomposition is 0.74 , which points out the potential of solar energy conversion into chemical energy.

Figure 5 shows the gas species mole fraction distribution along the porous catalyst bed of the MLTSRR. As can be seen, the methanol conversion is low in the beginning of the MLTSRR, while the $\mathrm{CH}_{3} \mathrm{OH}$ mole fraction decreases along the flow direction because of the endothermic reaction of $\mathrm{CH}_{3} \mathrm{OH}$ decomposition. For the thermal chemical reactions of $\mathrm{CH}_{3} \mathrm{OH}$, the mole fractions of the generated $\mathrm{H}_{2}$ and $\mathrm{CO}$ increase in the low direction, as can be seen in Figure $5 b$,c. The generated $\mathrm{H}_{2}$ mole fraction and $\mathrm{CO}$ mole fraction reach the highest value of 0.58 and 0.31 near the tube wall in the latter part of the MLTSRR. Due to the high working temperature near the tube wall in the latter part of the MLTSRR, the generated $\mathrm{H}_{2}$ and $\mathrm{CO}$ mole fraction near the tube wall in the latter part of the MLTSRR is higher than other positions.

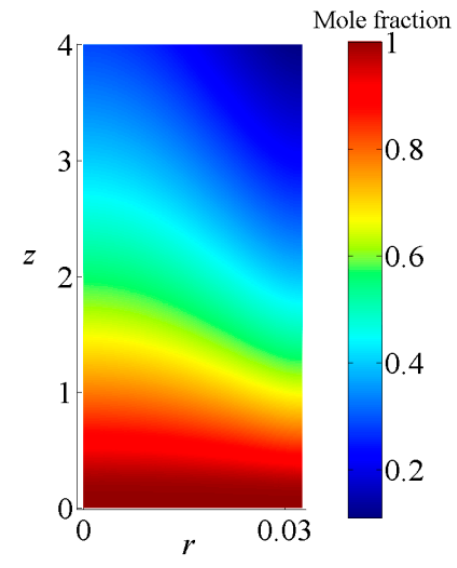

(a)

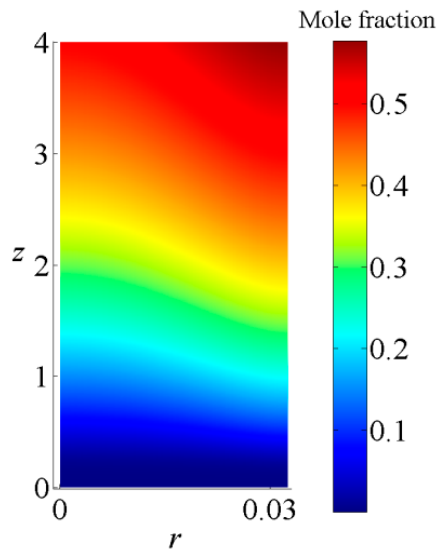

(b)

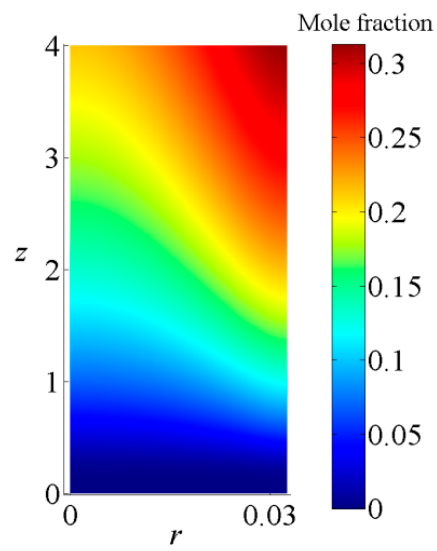

(c)

Figure 5. Mole fraction distribution in the catalyst bed. (a) $\mathrm{CH}_{3} \mathrm{OH} ;(\mathbf{b}) \mathrm{H}_{2}$; (c) CO.

\subsection{Comparison of the Thermochemical Performance between Methanol Decomposition and Methanol Steam Reforming}

Methanol steam reforming reaction is another process of methanol for solar energy utilization $\left(\mathrm{CH}_{3} \mathrm{OH}+\mathrm{H}_{2} \mathrm{O} \rightarrow \mathrm{CO}_{2}+3 \mathrm{H}_{2}, \Delta_{r} \mathrm{H}_{298 \mathrm{~K}}=50.7 \mathrm{~kJ} \mathrm{~mol}^{-1}\right)$. In this study, the two approach of methanol for solar energy utilization is compared. The methanol steam reforming reaction was conducted in the same solar receiver/reactor.

Figure 6 presents the comparison of temperature at the centre line $(r=0)$ of the catalyst bed for methanol decomposition and for methanol steam reforming at the same inlet temperature of $433 \mathrm{~K}$, the reactants feeding rate of methanol is $11.3 \mathrm{~kg} / \mathrm{h}$. We fixed the mole ratio of water/methanol at 1:1 for the methanol steam reforming. It is evident that when the same amount of solar energy is provided into the solar reactor, the catalyst bed temperature for the methanol decomposition is much higher. The methanol decomposition reaction occurs at a higher temperature. It is because the enthalpy of the methanol decomposition reaction is much higher than that of methanol steam reforming. 


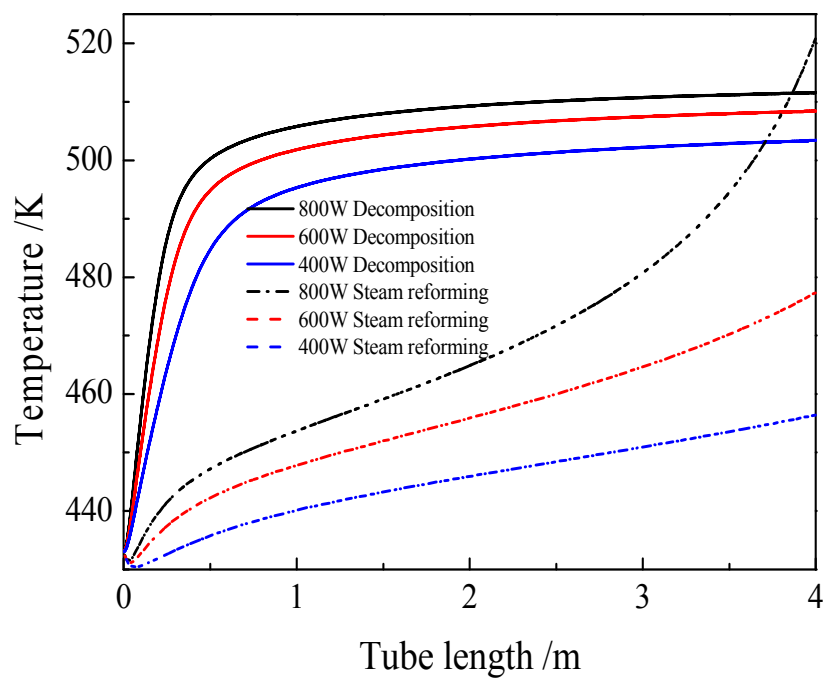

Figure 6. Catalyst bed temperature Variation with solar flux for steam reforming and methanol decomposition.

Figure 7 shows the comparison of the thermochemical efficiency for methanol decomposition and methanol steam reforming with the change of DNI under the same methanol feeding rate. It is clear that the thermochemical efficiency of the methanol steam reforming method is higher than that with methanol decomposition at low solar radiation, when the solar flux is $200 \mathrm{~W} / \mathrm{m}^{2}$, the thermochemical efficiency for methanol steam reforming improves by $7.2 \%$ when compared with methanol decomposition. When the solar flux is high, the thermochemical efficiency of the methanol decomposition method is higher. When the solar flux is $800 \mathrm{~W} / \mathrm{m}^{2}$, the thermochemical efficiency for methanol decomposition is $6.2 \%$ higher than that of methanol steam reforming.

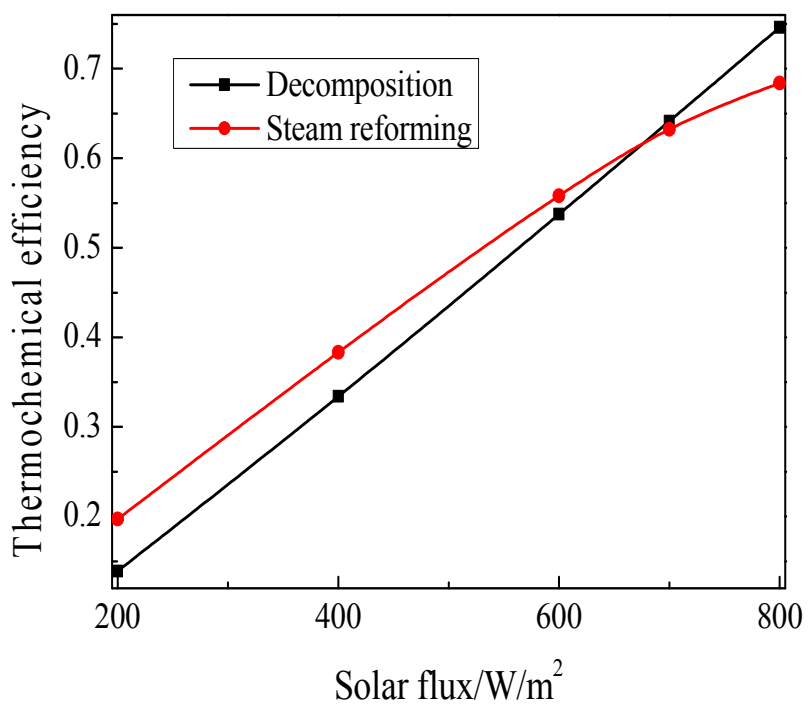

Figure 7. Thermochemical efficiency variation with solar flux for steam reforming and methanol decomposition.

\subsection{Characteristics of Different Operation Conditions}

In the operation of the MLTSRR, the annulus space between glass tube and receiver/reactor tube is vacuum. However, due to a variety of factors during operation, such as the broken of the glass-to-metal seal [15], the vacuum can be lost, moreover, the glass cover is broken. In this study, we investigated 
these three configurations: with vacuum in the annulus between glass tube and receiver/reactor tube, with air in the annulus under atmospheric pressure, and with the glass envelop completely removed when the reactants feeding rate of methanol, the reactants inlet temperature and the wind velocity are $13 \mathrm{~kg} / \mathrm{h}, 470 \mathrm{~K}$, and $2 \mathrm{~m} / \mathrm{s}$, respectively, and the length of the MLTSRR is $4 \mathrm{~m}$.

From Figure 8 we can see that under a same solar flux of $800 \mathrm{~W} / \mathrm{m}^{2}$, the methanol conversions are $0.54,0.46$ and 0.28 for the vacuum, air, and bare conditons, respectively, when the solar flux increases from $500 \mathrm{~W} / \mathrm{m}^{2}$ to $1000 \mathrm{~W} / \mathrm{m}^{2}$, methanol conversion falls by $6.8-8.9 \%$ with air in the annulus, as thermal losses increase because of increased conduction and convection in the air transferring heat from the receiver/reactor surface to the glass. Methanol conversion decreases by $21.8-28.9 \%$ when the glass is removed from the receiver/reactor.

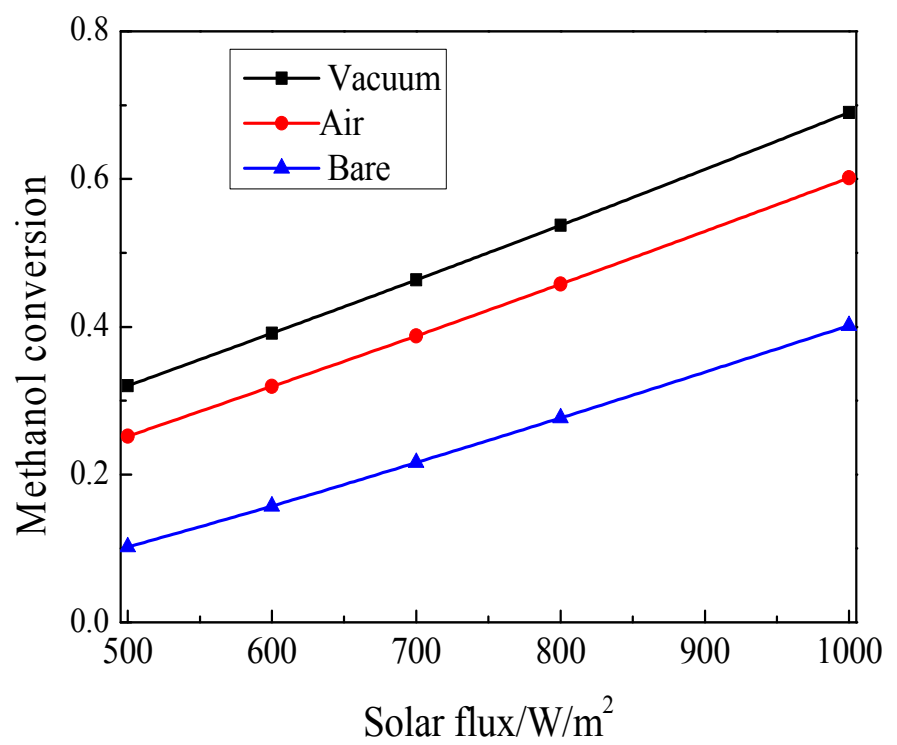

Figure 8. Variation of methanol conversion with solar flux in three configurations.

\section{Conclusions}

Based on the momentum equation in the porous catalyst bed, the governing mass conservation with chemical reaction, and energy conservation incorporating conduction/convection/radiation heat transfer, a multiphysics coupling model was developed for analyzing the properties of the MLTSRR. The main conclusions are as follows.

(1) The characteristics of chemical reaction, coupled heat transfer, and the whole components distributions and temperature fields in the receiver/reactor were obtained, when the reactants feeding rate of methanol is $11.3 \mathrm{~kg} / \mathrm{h}$, the DNI is $800 \mathrm{~W} / \mathrm{m}^{2}$, the efficiency of the solar energy transformed into the chemical energy can reach 0.74 .

(2) Two ways of methanol for solar energy utilization: methanol decomposition and methanol steam reforming were compared. The thermochemical efficiency of the methanol steam reforming can be $7.2 \%$, which is higher than that of methanol decomposition when the solar flux is $200 \mathrm{~W} / \mathrm{m}^{2}$, and the thermochemical efficiency of the methanol decomposition method can be $6.2 \%$ higher than that of methanol steam reforming when the solar flux is $800 \mathrm{~W} / \mathrm{m}^{2}$.

(3) The effects of the annulus vacuum space and the glass tube on the property of the MLTSRR were investigated. When the reactants feeding rate of methanol is $13 \mathrm{~kg} / \mathrm{h}$, the solar flux increases from $500 \mathrm{~W} / \mathrm{m}^{2}$ to $1000 \mathrm{~W} / \mathrm{m}^{2}$, the solar flux increases from $500 \mathrm{~W} / \mathrm{m}^{2}$ to $1000 \mathrm{~W} / \mathrm{m}^{2}$, the methanol conversion can fall by $6.8-8.9 \%$ with air in the annulus, and methanol conversion can decrease by $21.8-28.9 \%$ when the glass is removed from the receiver/reactor. 
Acknowledgments: The authors appreciate financial support provided by the National Natural Science Foundation of China (51606062, 51722606).

Author Contributions: Qinbin Liu and Yanjuan Wang conceived and designed the experiments; Yanjuan Wang performed the experiments; Jiwei Li and Can Chen analyzed the data; Jing Lei contributed reagents/materials/analysis tools; Yanjuan Wang wrote the paper.

Conflicts of Interest: The authors declare no conflict of interest.

\section{Nomenclature}

$\begin{array}{ll}\eta_{s o-t h} & \text { Efficiency of solar thermal energy converted into chemical energy } \\ n_{u n, \mathrm{CH}} \mathrm{OH} & \text { Mole flow rate of methanol which is not reacted } \\ n_{\mathrm{CH} \mathrm{H}_{3} \mathrm{OH}} & \text { Mole flow rate of methanol } \\ \varepsilon & \text { Porosity of the catalyst bed } \\ S_{\mathrm{A}} & \text { Effect area of the parabolic trough concentrators } \\ \kappa & \text { Hydraulic permeability } \kappa\left[\mathrm{m}^{2}\right] \\ X_{\mathrm{CH}} \mathrm{OH} & \text { Methanol conversion rate } \\ \eta & \text { Dynamic viscosity }[\mathrm{kg} /(\mathrm{m} \cdot \mathrm{s})] \\ \Delta_{r} \mathrm{H} & \text { Reaction enthalpy of methanol }[\mathrm{J} / \mathrm{mol}]\end{array}$

\section{References}

1. Steinfeld, A.; Palumbo, R. Solar thermochemical process technology. Encycl. Phys. Sci. Technol. 2001, 15, 237-256.

2. Fletcher, E.A. Solarthermal processing: A review. J. Sol. Energy Eng. 2001, 123, 63-74. [CrossRef]

3. Chueh, W.C.; Falter, C.; Abbott, M.; Scipio, D.; Furler, P.; Haile, S.M.; Steinfeld, A. High-flux solar-driven thermochemical dissociation of $\mathrm{CO}_{2}$ and $\mathrm{H}_{2} \mathrm{O}$ using nonstoichiometric ceria. Science 2010, 330, 1797-1801. [CrossRef] [PubMed]

4. Hirsch, D.; Steinfeld, A. Solar hydrogen production by thermal decomposition of natural gas using a vortex-flow reactor. Int. J. Hydrogen Energy 2004, 29, 47-55. [CrossRef]

5. Wang, J.J.; Lu, Y.C.; Yang, Y.; Mao, T.Z. Thermodynamic performance analysis and optimization of a solar-assisted combined cooling, heating and power system. Energy 2016, 115, 49-59. [CrossRef]

6. Hong, H.; Liu, Q.B.; Jin, H.G. Solar hydrogen production integrating low-grade solar thermal energy and methanol steam reforming. J. Energy Resour. Technol. 2009, 131, 012601. [CrossRef]

7. Sui, J.; Liu, Q.B.; Dang, J.G.; Guo, D.; Jin, H.G.; Ji, J. Experimental investigation of methanol decomposition with mid- and low-temperature solar thermal energy. Energy Res. 2011, 35, 61-67. [CrossRef]

8. Wang, J.J.; Yang, Y. Energy, exergy and environmental analysis of a hybrid combined cooling heating and power system utilizing biomass and solar energy. Energy Convers. Manag. 2016, 124, 566-577. [CrossRef]

9. Jin, H.; Sui, J.; Hong, H.; Wang, Z.; Zheng, D.; Hou, Z. Prototype of solar receiver/reactor with parabolic troughs. J. Sol. Energy Eng. 2007, 129, 378-381. [CrossRef]

10. Fogler, H.S. Elements of Chemical Reactor Engineering; Prentice-Hall: Englewood Cliffs, NJ, USA, 1986.

11. Kanouff, M.P.; Gharagozloo, P.E.; Salloum, M.; Shugard, A.D. A multiphysics numerical model of oxidation and decomposition in a uranium hydride bed. Chem. Eng. Sci. 2013, 93, 212-225. [CrossRef]

12. Jiang, C.J.; Trimm, D.L.; Wainwright, M.S.; Cant, N.W. Kinetic mechanism for the reaction between methanol and water over a Cu-ZnO- $\mathrm{Al}_{2} \mathrm{O}_{3}$ catalyst. Appl. Catal. A Gen. 1993, 97, 145-158. [CrossRef]

13. Wesselingh, J.A.; Krishna, R. Mass Transfer in Multicomponent Mixtures; Delft University Press: Delft, The Netherlands, 2000.

14. Poling, B.E.; Prausnitz, J.M.; O'connell, J.P. The Properties of Gases and Liquids; McGraw-Hill: New York, NY, USA, 2001.

15. Price, H.; Lüpfert, E.; Kearney, D. Advances in parabolic trough solar power technology. J. Sol. Energy Eng. 2002, 124, 109-125. [CrossRef]

(C) 2017 by the authors. Licensee MDPI, Basel, Switzerland. This article is an open access article distributed under the terms and conditions of the Creative Commons Attribution (CC BY) license (http:/ / creativecommons.org/licenses/by/4.0/). 